FRIEDRICH, JOHANNES, HETHITISCHES ELEMENTARBUCH. 1. Teil: Kurzgefasste Grammatik. 2. verbesserte und erweiterte Auflage. Heidelberg (C. Winter) $1960,8^{0}, 195$ str.

Preden poročam o drugi izdaji hetitske slovnice, katere avtor je profesor Johannes Friedrich, naj żaradi boljšega razumevanja nekoliko posežem nazaj in $\mathrm{z}$ nekaj potezami naznačim razvoj hetitologije.

I.

Hetiti so $v$ svojih napisih uporabljali klinopisno in svojo posebno hieroglifno pisavo; v naslednjih izvajanjih imamo $\mathrm{v}$ mislih le njihove klinopisne napise, ki so bili skoro vsi izkopani v bližini turške naselbine Boghazköi (sedaj Boghazkale), $145 \mathrm{~km}$ vzhodno od. Ankare. Ceprav je teh napisov na glinastih ploščicah mnogo manj kakor sumerskih ali babilonskih ali asirskih, so vendar po svoje zanimivi. Njihova prob̆lematika se začenja že pri imenu. Ime "Hetiti« se je namreč udomačilo pod vplivom M. Luth r ovega nemškega prevoda biblije, ki večkrat omenja Hitim (Gen, 23, Deut. 20, 17; 2. Sam. 11). Tudi v egiptovskih napisih se pojavija država naroda $H t^{\prime}$, kar so egiptologi po svoje vokalizirali kot Cheta. - Ko so leta 1887 v Egiptu v El-Amarni, v opuščeni prestolnici faraona Amenofisa IV. (Ehnatona), našli ostanke diplomatske korespondence tega faraona in njegovega očeta $s$ prednjeazijskimi vladarji, sta bili $\mathrm{v}$ tej zbirki tudi dve pismi iz faraonove korespondence s Tarhunduradujem, vladarjem dežele Arzave (najbrž v južni Mali Aziji). Norvežan J. A. Knudtzon je leta 1902 iz oblik e-eš-tu (prim. lat. esto) in iz sufiksov -miin -ti- (za moj in tvoj) domneval, da sta pismi pisani $v$ indoevropskem jeziku; pod vtisom hudih ugovorov je svojo domnevo umaknil!! - Leta $1906-07$ je nemški asiriolog Hugo $\mathrm{W}$ inckler pri vasi Boghazköi izkopal $\mathrm{v}$ razvalinah Hattušaša, prestolnice nekdanje Hetitske države, blizu 10.000 glinastih ploščic (pozneje se je to število povečalo na kakih 15.000), popisanih z babilonskim klinopisom, ki je bil tedaj že dobro čitljiv. Težave pa so bile $\mathrm{v}$ jezikovnem pogledu. Kar je bilo napisov $\mathrm{v}$ babilonskem in sumerskem jeziku (leksikalni teksti), so bili razumljivi; pozornost so vzbujali mnogoštevilni diplomatski dokumenti (pisma, državne pogodbe), iz katerih je znanstveni svet zvedel, da je skoro pol tisočletja (cca 1650-1200) obstajalà hetitska država, ki je okoli leta 1530 (ali 1560) začasno osvojila Babilon in tam zrušila Hammurabijevo

1 Prim. članek J. Friedrich, Altkleinasiatische Sprachen (Eibert, Reallexikon der Vorgeschichte ( $=\mathrm{RLV}$ ), I, 1924, 126-142) str. 129, § 5 . 
dinastijo, $\mathrm{v}$ naslednjih stoletjih tekmovala $\mathrm{v}$ Siriji z Egiptom, bila $\mathrm{v}$ menjajočih se odnošajih z državo Ahhijavo (najbrž v zapadnem delu Male Azije), dokler ni končno postala žrtev (t. i. egejskega preseljevanja pomorskih narodov - skoro ob istem času, ko je bila požgana Priamova Troja.

Večina tekstov je bila pisana $v$ istem jeziku, ki so ga že poznali iz obeh arzavskih pisem iz el-amarnskega arhiva. Za ta jezik se je naglo udomačila označba whetitski». Asiriolog Bedřich $\mathrm{Hrozný} \mathrm{je} \mathrm{vzbudil} \mathrm{veliko} \mathrm{senzacijo,}$ ko je leta 1915 dognal, da je bil to indoevropski jezik. Razen tega jezika so napisi ohranjeni še $\mathrm{v}$ dveh indoevropskih jezikih: eden se imenuje po deželi Palā (njene lege ne poznajo), drugi je luvijski; vendar je obojnih napisov znatno manj kakor hetitskih.

Vrh tega je nekaj napisov $\mathrm{v}$ hatijskem jeziku, ki ga je govorilo prebivalstvo, naseljeno pred Hetiti na pozneje hetitskem ozemlju. Nekaj tekstov je $v$ huritskem (ali mitanskem) jeziku. Za oba jezika je mogoče reči le, da nista ne indoevropska, ne semitska. Predvsem $v$ zvezi $z$ verskimi daritvenimi obredi hetitski teksti omenjajo petje $\mathrm{v}$ hatijskem (hattili), huritskem (hurlili) ali Iuvijskem (lu-u-i-li) jeziku, izgovarjanje obrednih besed $\mathrm{v}$ palaišsem (palaumnili) jeziku, medtem ko svojo govorico označujejo kot nāšili (KBo V 11, I, 3). Beseda nāšili je prislov, izveden od imena mesta Neša (Hrozný je tolmačil besedo "po naše«), tako da bi Hetite točneje imenovali Nešite. ${ }^{2}$

Hetitologijo, ki se je razvila ob novih tekstih, so precej časa gojili v Fragi, kamor se je B. Hrozný z Dunaja preselil, ter v Leipzigu (J. Friedrich). Berlinu ( $H$. Ehelolf), Heidelbergu (A. Götze) in Münchenu (F. Sommer). To razumemo, če upoštevamo, da so prva (in najuspešnejša) izkopavanja organizirali Nemci in sta si izkopane ploščice delila Prednjeazijski muzej v Beriinu (ozn. VAT) in Muzej za Stari Orient (ozn. Bo) v Carigradu. Dobro in hitro je bilo poskrbljeno za ediranje novih tekstov $\mathrm{v}$ zbirkah Keilschrifttexte aus Boghazköi $(=\mathrm{KBo})$ in Keilschrifturkunden aus Boghazköi (= KUB). Za poznavanje zlasti starejših tekstov si je pridobil velike zasluge Emil Forrer, Svicar, takrat priv. docent $\mathrm{v}$ Berlinu $\mathrm{z}$ zbirko Die Boghazköi-Texte in Umschrift, (Leipzig 1922-26), $\mathrm{v}$ kateri je $\mathrm{v}$ transkripciji objavil različne zgodovinske tekste. žal so ga nekatere preveč tvegane domneve zlasti glede države Ahhijave spravile $\mathrm{v}$ hudo nasprotje $\mathrm{z}$ ostalimi nemškimi hetitologi, katerih delovanje je bilo uspešno predvsem tudi zato, ker so pri obdelovanju noviin tekstov redno prijateljsko sodelovali. Morda ne bo preveč, če skušam z nekaj stavki vsaj označiti najvažnejše njihove zasluge za napredek hetitologije.

Hans Eh e l olf (1891-1939) je kot kustos Prednjeazijskega oddelka Berlinskih muzejev objavil devet zvezkov zbirke KUB. Kot upravnik izkopanih klinopisnih ploščic je imel nad njimi edinstven pregled; o tem pričajo njegove temeljite leksikalne študije. V muzeju je organiziral inventar vseh besed in oblik, ki se pojavijo kje $\mathrm{v}$ kảkem hetitskem napisu. Obdelal je obšịren tekst in ga je objavil leta 1924 kot "Hethitisches Ritual des Pāpanikri von Kumanak; pri tem delu $\mathrm{mu}$ je bil soavtor

\footnotetext{
2 Prim. J. Friedrich, RLV, I, str. 128.
} 
Ferdinand S o mmer (1875-1962), ki se je kot že štiridesetletnik in sloveč klasični filolog začel učiti akadskega (= babilonskega in asirskega) jezika in klinopisa. Od njegovih okoli 20 hetitoloških prispevkov, $\mathrm{s}$ katerimi je uvedel strogo kritično metodo $v$ hetitologiji, naj omenim vsaj monumentalni deli "Die Ahhijava-Urkunden" (1932) in "Die hethitisch-akkadische Bilingue des Hattušili Iı (1938) ter še njegovo zadnjo knjigo wHethiter und Hethitisch، (1947), ki se je z njo žal prezgodaj poslovil od hetitologije. Njegova knjižnica $\mathrm{z}$ bogato zbirko listkovnega jezikoslovnega gradiva je bila med vojno uničena ob bombnem napadu; drugače zelo dobrodušni učenjak tega ni mogel preboleti, čeprav je svojo učno delavnost nadaljeval do zadnjin let svojega življenja (1875-1962) kot emeritirani profesor v Münchenu.

Albrecht G o e t z e, sedaj profesor Yale-ske univerze $v$ New Havenu (ZDA), se je uveljavil $z$ ediranjem zgodovinskih napisov. $V$ zvezi $s$ tem je jezikovno obdelal več obširnejših tekstov, kakor "Življenjsko poročilo Hattušiliša III" (1925, 1930); obtožbo zoper upornega "Madduvattaša» (1928); mMuršiliševe molitve zoper kugo» (1930), "Muršiliševe anale» (1933). Poleg kratkega očrta hetitske zgodovine je napisal za "Handbuch des Altertums", temeljno "Kulturno zgodovino Male Azije« (1. izd. 1933; 2. izd. 1957). Kot eden izmed prvih pregnancev nacizma je našel v New Havenu svoj novi dom. Čeprav je tudi tu objavil dve knjigi s hetitološkega področja: "Ritual (žene) Tunnavi» (1938) in monografijo o deželi Kiz(zu)vatni (1940) ter ga po vojni najdemo med soustanovitelji revije Journal of Cuneiform Studies, ga vendar močno zaposlujejo izkopavanja $\mathrm{v}$ Nippurju, $\mathrm{ki}$ jih on vodi, in novi akadski "Zakoni iz mesta Ešnune», ki jih je odkril leta $1948 \mathrm{v}$ Bagdadu.

Johannes F ri e d ri c h (r. 1893) je kot klasični filolog prešel k hetitologiji. Najože povezan $z$ univerzo $v$ Leipzigu, je leta 1921 sodeloval pri prvem prevodu "Hetitskih zakonov", ki ga je oskrbel asiriolog Henrik Zimmern. Medtem ko se je le-tà pozneje zopet povrnil $\mathrm{k}$ akadskim in sumerskim tekstom, je J. Friedrich nadaljeval s filološko obdelavo pravnih tekstov in je zaključil to svoje delo $\mathrm{z}$ monumentalno izdajo, $\mathrm{z}$ novo transkripcijo, prevodom in (žal precej kratikim) komentarjem whetitskih zakonov" ("Hethitische Gesetze Leiden 1959). S podobno ljubeznijo se je lotil, zopet z jezikovne strani, šestih vazalnih državnih pogodb $(1926,1930)$. V dveh zvezkih zbirke Der Alte Orient (1925) je posredoval prevod nekaterih posebno značilnih zgodovinskih in verskih napisov. Velike uspehe je dosegel tudi kot slovničar. Citiral sem že njegov članek o starih maloazijskih jezikih iz leta 1924, ki vsebuje dejansko očrt hetitske slovnice, kolikor je bil takrat mogoč. Ta slovniški poskus je razširil leta $1931 \mathrm{~s}$ knjižico (78 str.) "Hethitisch und ,kleinasiatische Sprachen'". (Berlin). Leta 1940 je izdal prvo izdajo svoje wkratke" (kurzgefasste) slovnice, ki ji je leta 1946 dodal zbirko nekaj značilnih hetitskih tekstov $\mathbf{s}$ slovarčkom in kratkimi pojasnili. Oboje je označil kot svoj "Hethitisches Elementarbuch". Leta 1960 je sledila druga izdaja hetitske slovnice, poleg nje pa zopet dodana zbirka tekstov v klinopisu s seznamom klinopisnih znakov - o slovnici spregovorimo še posebej. Leta 1952 je mravljično pridni 


\section{Viktor Korošec}

avtor objavil svoj hetitski slovar ${ }^{3}$ Pri tem naj vsaj omenim, da je med njegovimi 21 knjigami in 157 članki ter ocenami, ki jih našteva Festschrift Johannes Friedrich (zum 65. Geburtstag am 27. August 1958 gewidmet) (str. 487-503) samo pretežni del hetitološki. Med drugimi deli najdemo namreč npr. "Uvod. v urartejščino" (1933); "Male prispevke k huritski slovnici« (1939); „Feničansko-punsko slovnico" (1951) in »Kurze Grammatik der alten QuichéSprache im Popol Vuhu (1955).

Hitri napredek hetitologije je vzbudil zanimanje zanjo tudi drugod. V Franciji je pokojni Louis Delaporte ustanovil revijo »Revue Hittite et. Asianique«. V svojem "Manuel de langue Hittite (1929-1933) je objavil tudi hetitsko slovnico (1929). V knjigi Les Hittites' je v lahko umljivi obliki povzel vsa dotlejšnja dognanja o Hetitih (1936). - Predvsem kot kulturna zgodovinarja sta obravnavala Hetite Eugène $\mathrm{Cavaig} \mathrm{n}$ a $\mathrm{c}^{5}$ in Georges $\mathrm{C}$ o n t e n a u'. - Prav tako iz vrst klasičnih filologov je vzrastel Emmanuel La r o c he, ki nadaljuje $\mathrm{z}$ izdajanjem $"$ Revue Hittite et Asianique in marljivo posega na različna področja, tako da ga štejejo med prve hetitologe v svetovnem merilu.

V Ameriki je Edgar $\mathrm{H}$. S t u r te van t leta 1933 objavil svojo primerjalno slovnico (A Comparative Grammar of the Hittite Language), ki ji je leta 1936 sledila že druga izdaja hetitskega besednjaka (A Hittite Glossary). V Chicagu se je $z$ vrsto temeljitih študij uveljavil kot eden najbolj pomembnih Hans G. Gü.ter bo ck, ki ga je usoda vodila od predavalnic Ehelolfa in Friedricha preko Ankare in Uppsale. - Za obravnavanje hetitskih zgodovinskih tekstov dolguje hetitologija mnogo Henriku Otten $u$ (sedaj Marburg ob Lahni); on in Bernard Rosenkranz (Köln) proučujeta marljivo tudi luvijsketekste. - Delo. F. Sommerja nadaljuje v Münchenu z izrednim elanom njegova učenka Annelies $\mathrm{K}$ a m m e $\mathrm{n} \mathrm{h} \mathrm{u} \mathrm{b} \mathrm{e} \mathrm{r} \mathrm{z} \mathrm{obsežnimi} \mathrm{slovniškimi} \mathrm{in} \mathrm{leksikaInimi}$ àeli (prim. "Hippologia hethitica《 1961) in $\mathrm{s}$ proučevanjem protohatiških tekstov. - Od učencev J. Friedricha deluje R. Ra noszek v Varšavi, in iz mlajše generacije je Einar von $S \mathrm{chuler}$ obdelal t. i. službene instrukcije. $\Upsilon$ Pragi poleg prof. Luborja $M$ a to $u$ ša, ki ga zajema $v$ veliki meri sumerologija, deluje Vladimir S o u č e k, v Berlinu mladi Kaspar R i e m s c h n e i de r.

Kot avstrijskega hetitologa naj omenimo jako delavnega filologa $\mathrm{H}$. K r onasserja.

V Angliji se bavita s hetitsko problematiko zlasti filolog R. A. C ros sl and (Sheffield) in O. R. Gurney (Oxford), čigar knjižica "The Hittites" je v prikupni obliki kot Penguin-book uspešno popularizirala znanje o hetitski kulturi in njenih problemih.

Na Danskem je iz starejše generacije omeniti vsaj jezikoslovca Holgerja Pedersena ("Hittitisch und die anderen indoeuropäischen Sprachen",

${ }^{3}$ Hethitisches Wörterbuch. Kurzgefasste kritische Sammlung der Deutungen. hethitischer Wörter. Heidelberg (C. Winter): 1952. Doslej sta izšla leta 1957 in 1961 dva dodatka; tretjega avtor pripravlja (pismeno sporočilo).

4 V zbirki L'Evolution de l'Humanité, 1936. Paris.

${ }^{5}$ Le Problème Hittite. Paris 1936.

${ }^{6}$ La Civilisation des Hittites et des Hurrites du Mitanni. Paris 1934. 
1938), iz mlajše J. Holta. Le-ta je prevedel v danščino tudi whetitske zakoner.

Enako, nikakor nelahko delo je v Sovjetski zvezi uspešno opravila agilna I. M. Dunajevskaja (Leningrad). Razen nje se kot filolog uveljavlja V. V. I vanov (Moskva).

Tudi naša Ljubljana ima v Bojanu c o p u hetitologa, čigar filološki-etimološki prispevki so zelo cenjeni $v$ mednarodni hetitologiji. ${ }^{7}$

II.

Po tem dolgem uvodu naj končno poročam o drugi izdaji J. Friedrichove hetitske slovnice.

V njej najdemo že splošno udomačeno razvrstitev snovi na tri oddelke: I. nauk o pisavi in glasovih; II. oblikoslovje in III. sintaksa. Nato je, kakor v prvi izdaji, dodan IV. oddelek, ki obsega najpotrebnejša pojasnila ıza razumevanje akadskih in sumerskih besednih obliku. Nov pa je V. oddelek o Iuvijski slovnici.

$\checkmark$ predgovoru avtor pove (str. 15), da je obdržal $v$ glavnem isto ureditev, kakor je bila $v$ prvi izdaji, pač pa je uz boljšo razčlenitvijo in s śtevilnimi dopolnitvami in zboljšanji巛 skušal pokazati napredek $v$ zadnjih dvajsetih letih, ki so potekla od prve izdaje. V prvi izdaji je avtor naštel imena slovničarjev, ki so dotlej objavili hetitske slovnice; zdi se mi škoda, da tega ni ponovil v drugi izdaji, saj mladi učenci hetitščine na ta način najlaže razumejo težave in nedvomne zasluge za nagli napredek hetitologije.

Lepo se bere precej predelani uvod (str. 15), ki pregledno našteva jezike napisov, najdenih v Boghazköi. Ko avtor ugotavlja, da so Hetiti sami svoj jezik imenovali nesiški, se vendarle odloči za udomačeno besedo shetitski«, vendar $z$ dostavkom $» k$ lin o is n a hetitščinak, da se tako loči od hieroglifne ali slikovne hetitščine, tj. jezika, uporabljanega na hieroglifnih napisih, predvsem iz Severne Sirije, skoro pol tisočletja po uničenju maloazijske Hetitske države. J. Friedrich prišteva v a n a t o ls k o skupino indoevropskih jezikov naslednje: klinopisno hetitščino, Iuvijski, palāiski, slikovni hetitski in (po E. La rochevih dognanjih tudi) likijski jezik.

Splošno lahko trđimo, da se v drugi izdaji J. Fr.-ove slovnice lepo vidi pomemben napredek, ki ga je hetitologija napravila $\mathrm{v}$ zadnjih 20 letih. Kajpak ima pri tem znaten delež J. Fr. sam s svojimi raziskovanji, od mlajše generacije pa $A$. Kammenhuber in E. La.roche. - Posrečeno se mi zdi, da avtor pri oštevilčenju posameznih odstavkov (v prvi izdaji jih je $374, \bar{v}$ drugi 411) poleg novih številk navaja $v$ oklepaju tudi stare; na ta način se že na zunaj spozna, kateri odstavki so novi. Tudi $\nabla$ starih odstavkih, ki so pre-

${ }^{7}$ Opazka uredništva. - V preveliki skromnosti avtor ne omenja sebe, čeprav je prof. Ko r o š e c mednarodno priznan strokovnjak za sumersko, akadsko in hetitsko pravo in hkrati strokovnjak za te jezike. Eno njegovih najbolj znanih del je Hethitische Staatsverträge (Leipzig 1931). Sodeluje tudi pri leksikonu za asiriologijo. Stalno aktivno sodeluje na mednarodnih orientalističnih kongresih. Predvsem njemu pripada zasluga, da imamo Slovenci svoje mesto $v$ tej znanstveni panogi. 
vzeti iz prve izdaje, je pogosto marsikaj spremenjeno: včasih so dodani novi primeri, novi pododstavki so vrinjeni ali pa je razporeditev drugačna. Tako npr. novi drugi (2.) odstavek lepo pojasnjuje pomen diakritičnih znamenj pri homofonih znakih (= enako se glasečih zlogih, ki se lahko pišejo z različnimi znaki) in tako lepo umljivo uvaja tudi začetnika samouka $\mathrm{v}$ posebnosti klinopisne pisave (str. 21).

Glede izgovarjave naj bo kot novost omenjeno, da so Hetiti končnico edninskega imenovalnika na $-\check{s}$ najbrž izgovarjali kot $-s$ (str. 43 , odst. 57 a). Dalje trđi avtor v drugi izdaji, da so Hetiti imeli spočetka osem (ne šest) sklonov; kajpak je bil zvalnik zelo redek; dajalnik in mestnih (lokalis) sta se razlikovala samo $\mathrm{v}$ stari hetitščini. Novo je tudi, da kot končnico rodilnika eđnine omenja samo -ă ne tudi -š (str. 43).

Deloma razširil, deloma na novo je avtor uvrstil podatke o tujih elementih $\mathrm{v}$ hetitski sklanjatvi (str. 59) in konjugaciji (str. 113 s). Pri deklinacijah ugotavlja akadske, luvijske in huritske vplive; pri glagolih pa našteva luvijske vplive.

Tudi pri obravnavanju glagolov opazimo v drugi izdaji precejšen napredek. Nekatera paradigmata so spremenjena, včasih naletimo na spremembe $\checkmark$ razredih; tako npr. nov razred $I, 1$, ki združuje večzložne glagole na -ešin $-a h h$ - ( $v$ prvi slovnici so glagoli na $-a h h$ uvrščni v podrazred $I, 1, e, \beta$ ). Prav tako je za nekatere glagoie, $\mathrm{ki}$ jih $\mathrm{v}$ prvi izdaji ni uvrstil $\mathrm{v}$ nobeno skupino (npr. pāi- witiu in uva- "pritiu), sedaj predvidel novo skupino ( $\mathrm{I}, 2 \mathrm{~d}$ ). - Glede označb nominainih glagolskih oblik je avtor sledil pobudi A. Kammen$h \mathrm{u}$ b e $\mathrm{r}$ j e ve in tako ne govori več o gerundiju in gerundivu, ampak razlikuje infinitiv $\mathrm{I}$ in II, supinum in glagolski samostalnik (str. 77).

Oddelek o sintaksi (str. 115-169) je zelo spremenjen, saj ima enajst novin odstavkov. Avtor omenja, da je pri tem uporabljal neobjavljeni rokopis obdelave, ki jo je sestavil Drohla (žal nam pisec ni bliže označèn). V podrobnosti se tu ni mogoče spuščati.

Oddelek o oblikovnih posebnostih akadskih in sumerskih besed (str. 170 do 182) je zeio koristen hetitologu, ki še ni predelal slovnic teh jezikov. $V$ hetitskih tekstih naletimo namreč pogosto na sumerske in akadske besede, ki so vpletene $v$ hetitsko besedilo. Negotovo je, kako so jih Hetiti izgovarjali: ali. po tuje, ali pa po svoje shetitsko«. J. Fr. posrečeno vzporeja te ideograme $z$ današnjimi številkami in $z$ merskimi enotami, ki jih $\mathrm{v}$ raznih jezikih različno izgovarjamo, čeprav jih enako pišemo; njemu se zdi verjetnejše, da so jih Hetiti izgovarjali večidel $\mathrm{v}$ hetitskem jeziku (str. 22). Slovnica, ki daje kratek pregled akadskih in sumerskih značilnosti, vrh tega opozarja na posebnosti, ki so jih Hetiti uvedli glede teh tujih oblik v svojih tekstih; očitno je, da jim je uporabljanje akadskega jezilka povzročalo včasih težave. - Morda bi bilo tu omeniti knjigo René L a b a t, L'akkadien de Boghaz-Köi. Étude sur la Langue des Lettres, Traités et Vocabulaires Akkadiens trouvés à BoghazKöi (Bordeaux 1932). Hetitologu nudi to delo dragoceno pomoč.

Nov je oddelek, ki naj na straneh 183-195 kratko povzame najvažnejše, kar je doslej dognanega o luvijski slovnici. Kakor J. Fr. uvođoma pove, citira. 
Kar sumarno oba pionirja na tem področju, to sta: E. L a r o c h e („Esquisse de grammaire louvite $\mathrm{v}$ Dictionnaire de la langue louvite) in $\mathrm{A}$. $\mathrm{K}$ a $\mathrm{m} \mathrm{men}$ hu b e r (Esquisse de la grammaire palāite, oboje 1959). V tekstu sta pa pri sklonih citirani tudi deli B. R os enkranz, Beiträge zur Erforschung des Luvischen (Wiesbaden 1952) in $\mathrm{H}$. Otte $\mathrm{n}$, Zur grammatikalischen und lexikalischen Bestimmung des Luvischen (Berlin 1953).

V svojem kratkem pregledu luvijske slovnice, za katerega smo avtorju zares hvaležni, obravnava najprej glasoslovje, nato samostalnike, zaimke, glagol in členice. Morda naj bralcu ponazorimo z nekaj primeri razliko med hetitskim in luvijskim jezikom. Hetitski ešdu (= naj bo, latinsko esto) je c.šdu $\mathrm{v}$ luvijskem in $\mathrm{v}$ palaiskem jeziku. Glagol ustoriti» je $\mathrm{v}$ hetitskem jeziku $i j a$-, v luvijskem aja-. Izraz za ndober" je hetitsko aššu, luvijsko vašu-. Oče in mati se hetitsko imenujeta attaš in annaš, luvijsko pa tatiš (likijsko tedi-) in anniš. Nekajkrat posega avtor $\mathrm{s}$ svojimi navedbami tudi $\mathrm{v}$ hieroglifno hetitščino.

J. Friedrich izraža v predgovoru željo, naj bi tudi razširjena druga izdaja "pridobivala novih prijateljev proučevanju starih maloazijskih jezikov" (str.5). Prepričan sem, da se bo ta njegova želja $\mathrm{v}$ veliki meri izpolnila.

Njegova slovnica se, kakor splošno vse njegove publikacije, odlikuje po jasnosti in lahki umljivosti tudi glede zamotanih vprašanj. Glede spornih zadev je skrajno oprezen, medtem ko dognanja podpira z navajanjem posameznih mest iz virov. Zato mislim, da bo vsak hetitolog avtorju hvaležen, da $\mathrm{mu}$ je $\mathrm{z}$ novo spopolnjeno drugo izđajo olajšal umevanje hetitskih virov. Nova slovnica bo veljala kot važen mejnik $\mathrm{v}$ naglem in uspešnem razvoju hetitoIogije. 